\title{
Application of GNSS Interferometric Reflectometry for the Estimation of Lake Ice Thickness
}

\author{
Yusof Ghiasi ${ }^{1, *} \mathbb{D}$, Claude R. Duguay ${ }^{1,2} \mathbb{D}$, Justin Murfitt ${ }^{1}\left(\mathbb{D}\right.$, Joost J. van der Sanden ${ }^{1,3}$, \\ Aaron Thompson ${ }^{1}$, Hugo Drouin ${ }^{3}$ and Christian Prévost ${ }^{3}$ \\ 1 Department of Geography and Environmental Management, University of Waterloo, Waterloo, ON N2L 3G1, \\ Canada; crduguay@uwaterloo.ca (C.R.D.); jmurfitt@uwaterloo.ca (J.M.); \\ Joost.vandersanden@canada.ca (J.J.v.d.S.); aaron.thompson@uwaterloo.ca (A.T.) \\ 2 H2O Geomatics Inc., Waterloo, ON N2L 1S7, Canada \\ 3 Canada Centre for Mapping and Earth Observation, Natural Resources Canada, Ottawa, ON K1A 0E4, \\ Canada; hugo.drouin@canada.ca (H.D.); christian.prevost@canada.ca (C.P.) \\ * Correspondence: syghiasi@uwaterloo.ca
}

Received: 3 July 2020; Accepted: 21 August 2020; Published: 23 August 2020

\begin{abstract}
Lake ice thickness is a sensitive indicator of climate change largely through its dependency on near-surface air temperature and on-ice snow mass (depth and density). Monitoring of the seasonal variations and trends in ice thickness is also important for the operation of winter ice roads that northern communities rely on for the movement of goods as well as for cultural and leisure activities (e.g., snowmobiling). Therefore, consistent measurements of ice thickness over lakes is important; however, field measurements tend to be sparse in both space and time in many northern countries. Here, we present an application of L-band frequency Global Navigation Satellite System (GNSS) Interferometric Reflectometry (GNSS-IR) for the estimation of lake ice thickness. The proof of concept is demonstrated through the analysis of Signal-to-Noise Ratio (SNR) time series extracted from Global Positioning System (GPS) constellation L1 band raw data acquired between 8 and 22 March (2017 and 2019) at 14 lake ice sites located in the Northwest Territories, Canada. Dominant frequencies are extracted using Least Squares Harmonic Estimation (LS-HE) for the retrieval of ice thickness. Estimates compare favorably with in-situ measurements (mean absolute error $=0.05 \mathrm{~m}$, mean bias error $=-0.01 \mathrm{~m}$, and root mean square error $=0.07 \mathrm{~m}$ ). These results point to the potential of GPS/GNSS-IR as a complementary tool to traditional field measurements for obtaining consistent ice thickness estimates at many lake locations, given the relatively low cost of GNSS antennas/receivers.
\end{abstract}

Keywords: GNSS; GPS; interferometry; reflectometry; lake ice thickness

\section{Introduction}

Lake ice is a significant landscape feature in the winter season at northern latitudes and plays a key role in climate moderation and the energy balance [1]. Lake ice conditions, notably the length of the ice season and ice thickness, have a significant impact on the economy of northern regions through their influence on transportation, travel, fishing, and recreation activities [2]. Therefore, accurate knowledge about lake ice properties, such as thickness, is necessary. However, manual measurement of ice thickness is time-consuming and can be expensive to perform in remote locations. Automated approaches are a possible alternative. For example, upward facing sonar systems such as the shallow water ice profiler (SWIP) have been used to obtain lake ice thickness throughout the ice season at both temperate and subarctic latitudes [3,4]. Ground-based radar systems such as Frequency-Modulated Continuous-Wave (FM-CW) radar have also proven effective for obtaining ice thickness at X-and $\mathrm{Ku}$-band [5]. However, these systems are pricey to both acquire (e.g., tens to hundreds of thousands of 
dollars) and deploy at multiple locations. Furthermore, while satellite retrievals of ice thickness from passive microwave and radar altimetry missions can provide reasonable estimates (root mean square errors ca. $0.15-0.30 \mathrm{~m}$ and correlations $>0.65$ ), these methods are limited to larger lakes due to the low spatial resolution of the associated sensors (ca. $\mathrm{km}$ to tens of $\mathrm{km}$ footprints) [6,7]. Therefore, there is the need for a lower cost solution that can provide high-resolution estimations of ice thickness.

Non-positioning applications of Global Navigation Satellite System (GNSS) are frequently used as a low-cost method in various domains of application (e.g., atmospheric and surface monitoring). GNSS Interferometry Reflectometry (GNSS-IR) is one of the most common remote sensing approaches among non-positioning GNSS applications to measure surface properties, including soil moisture content [8], snow depth [9], and vegetation water content [9]. Although the potential of GNSS-IR for sea ice detection [10] and ice thickness estimation [11,12] has been explored, there has been no direct field application for measurements over ice cover at multiple lake sites.

In this letter, we demonstrate and suggest the potential use of permanent or semi-permanent GNSS-IR stations for estimating lake ice thickness using data acquired during March 2017/2019 field campaigns at 14 sites in the Northwest Territories, Canada. GNSS antennas/receivers were installed concurrently near locations where manual ice thickness measurements were made. The dominant frequencies of signal-to-noise ratio (SNR) of reflected signals from the Global Positioning System (GPS) constellation are extracted using the Least-Squares Harmonic Estimation (LS-HE) method to estimate the vertical distance from the reflective surface, which is derived from the distance between the GPS antenna phase centre and the ice-water interface. Ice thickness retrievals are shown to be in good agreement with in-situ measurements.

\section{Methodology}

\subsection{Ice Thickness Retrieval from $S N R$}

The SNR can be derived from the raw data recorded by any GNSS receiver. According to [9], the SNR has a sinusoidal form that varies with satellite elevation angle $(e)$ and can be written as follows:

$$
S N R=A(e) \sin \left(\frac{4 \pi H}{\lambda} \sin (e)+\phi\right)
$$

where $A(e), H$, and $\phi$ denote amplitude, antenna height and phase shift, respectively. The carrier wavelength is represented by $\lambda$, which is $19 \mathrm{~cm}$ for GNSS L1 band. Next, the frequency $(4 \pi H / \lambda)$ is estimated using univariate LS-HE as suggested in [13] to retrieve the antenna height from the reflective surface. The periodogram presented in Figure 1 is the output of the LS-HE method where the major peaks represent the distance between the antenna phase centre and the ice-water interface. Readers are referred to [9] for further details on the approach. This example of frequency waveform was obtained from the SNR time series recorded by the GNSS receiver at Waite Lake (Site ID 6; see Table 1) with dominant peaks related to the vertical distance between the antenna phase centre and the reflecting surface. Since the GNSS antenna is installed on the ice surface, the antenna phase centre height (i.e., the distance between the antenna phase centre and the ice-water interface) shown by the waveform is used to estimate total ice thickness. However, because the antenna phase centre is located above the ice surface, an offset must be applied to obtain the distance between the ice surface and ice-water interface. For this example, an antenna phase centre height of $0.75 \mathrm{~m}$ was retrieved. After applying the offset, ice thickness was determined to be $0.68 \mathrm{~m}$, while the manual field measurement was $0.73 \mathrm{~m}$.

The reasons that LS-HE is preferred rather than any other periodogram, such as the Fourier transform, are twofold: (1) the time intervals between data sampling do not need to be equal, and (2) other dominant frequencies can be used to obtain the antenna height from multiple reflective layers. However, in the present study, the only layer considered as the reflective surface is the ice-water interface since it is known that the L-band signal penetrates well into the freshwater ice column overlain by dry snow $[14,15]$ and the dominant reflection is at the ice-water interface due to the large dielectric 
contrast between the two layers. Figure 2 illustrates the principle behind the GNSS-IR retrieval method for ice thickness estimation during the ice growth season.

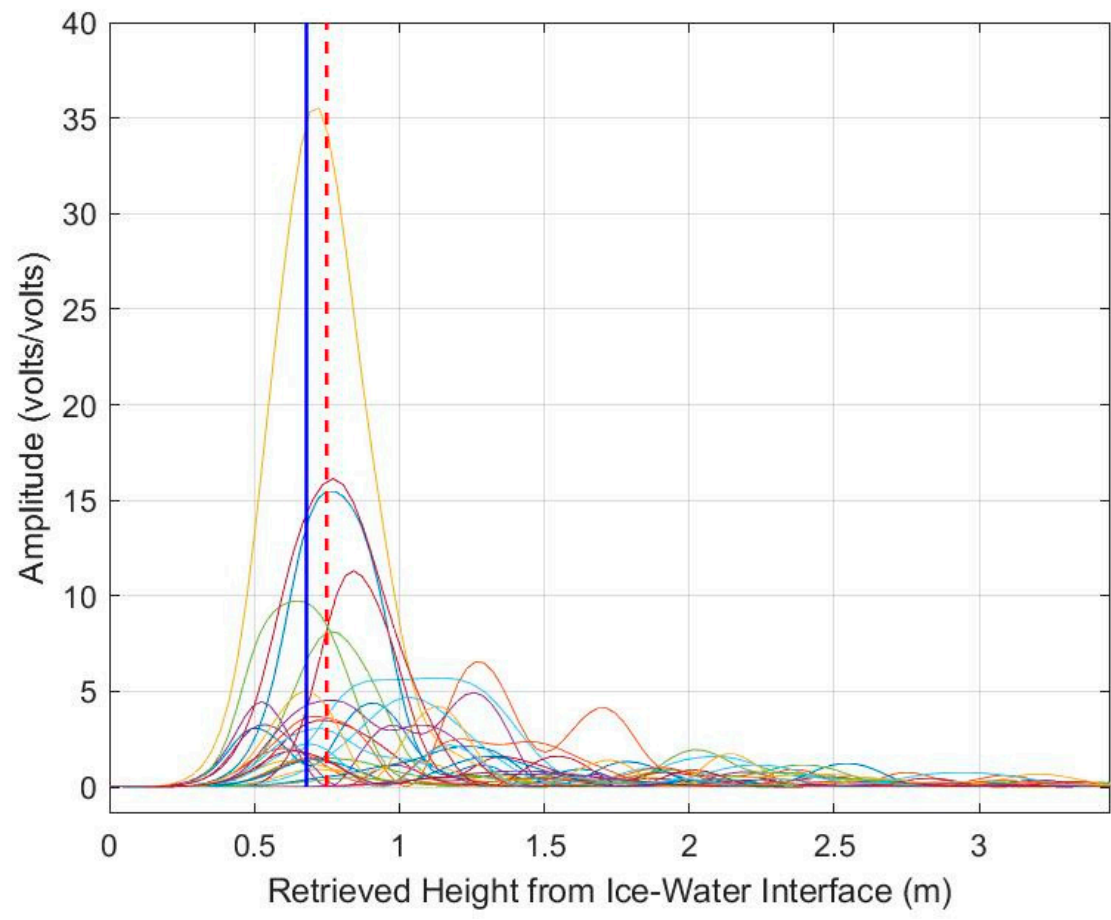

Figure 1. SNR spectrum obtained by LS-HE for a GNSS antenna installed on the top of the ice surface at Waite Lake (Site ID 6 in Table 1). Different colors represent the spectrum from different satellites. The dashed red line shows the median of the dominant peaks obtained from each satellite and is determined to be the antenna phase centre height (the distance between the antenna phase centre and the ice-water interface) $(0.75 \mathrm{~m})$. The solid blue line shows the estimated ice thickness of $0.68 \mathrm{~m}$ following application of the offset to account for the distance between the ice surface and the antenna phase centre.

Table 1. General description of field sites along with corresponding geographical coordinates, deployment dates and ice thickness measurements from drilled boreholes.

\begin{tabular}{|c|c|c|c|c|c|}
\hline \multirow{2}{*}{ GPS Site ID } & \multirow{2}{*}{ Lake Name } & \multicolumn{2}{|c|}{$\begin{array}{l}\text { Geographical Coordinates } \\
\text { (Decimal Degrees) }\end{array}$} & \multirow{2}{*}{ Date } & \multirow{2}{*}{$\begin{array}{c}\text { Measured Ice } \\
\text { Thickness } \\
\text { (m) }\end{array}$} \\
\hline & & Latitude & Longitude & & \\
\hline 1 & Gordon Lake & 63.04556 & -113.2169 & 9 March 2017 & 0.82 \\
\hline 2 & Gordon Lake & 62.95611 & -113.2667 & 10 March 2017 & 0.90 \\
\hline 3 & Gordon Lake & 63.09444 & -113.2186 & 8 March 2017 & 0.88 \\
\hline 4 & Gordon Lake & 62.95361 & -113.2331 & 10 March 2017 & 0.86 \\
\hline 5 & Gordon Lake & 62.9425 & -113.3003 & 14 March 2019 & 1.02 \\
\hline 6 & Waite Lake & 62.8475 & -113.3236 & 16 March 2019 & 0.73 \\
\hline 7 & Pensive Lake & 62.73028 & -113.3075 & 17 March 2019 & 0.80 \\
\hline 8 & Murray Lake & 63.01222 & -113.4606 & 12 March 2019 & 0.86 \\
\hline 9 & Ross Lake & 62.69942 & -113.24374 & 17 March 2019 & 0.94 \\
\hline 10 & Dome Lake & 62.76222 & -113.2561 & 18 March 2019 & 0.79 \\
\hline 11 & Fenton Lake & 63.02222 & -112.9669 & 14 March 2019 & 0.85 \\
\hline 12 & Upper Ross Lake & 62.72933 & -113.15086 & 17 March 2019 & 1.02 \\
\hline 13 & Noell Lake & 68.51149085 & -133.5497 & 21 March 2019 & 0.89 \\
\hline 14 & Noell Lake & 68.51185952 & -133.551323 & 22 March 2019 & 0.89 \\
\hline
\end{tabular}




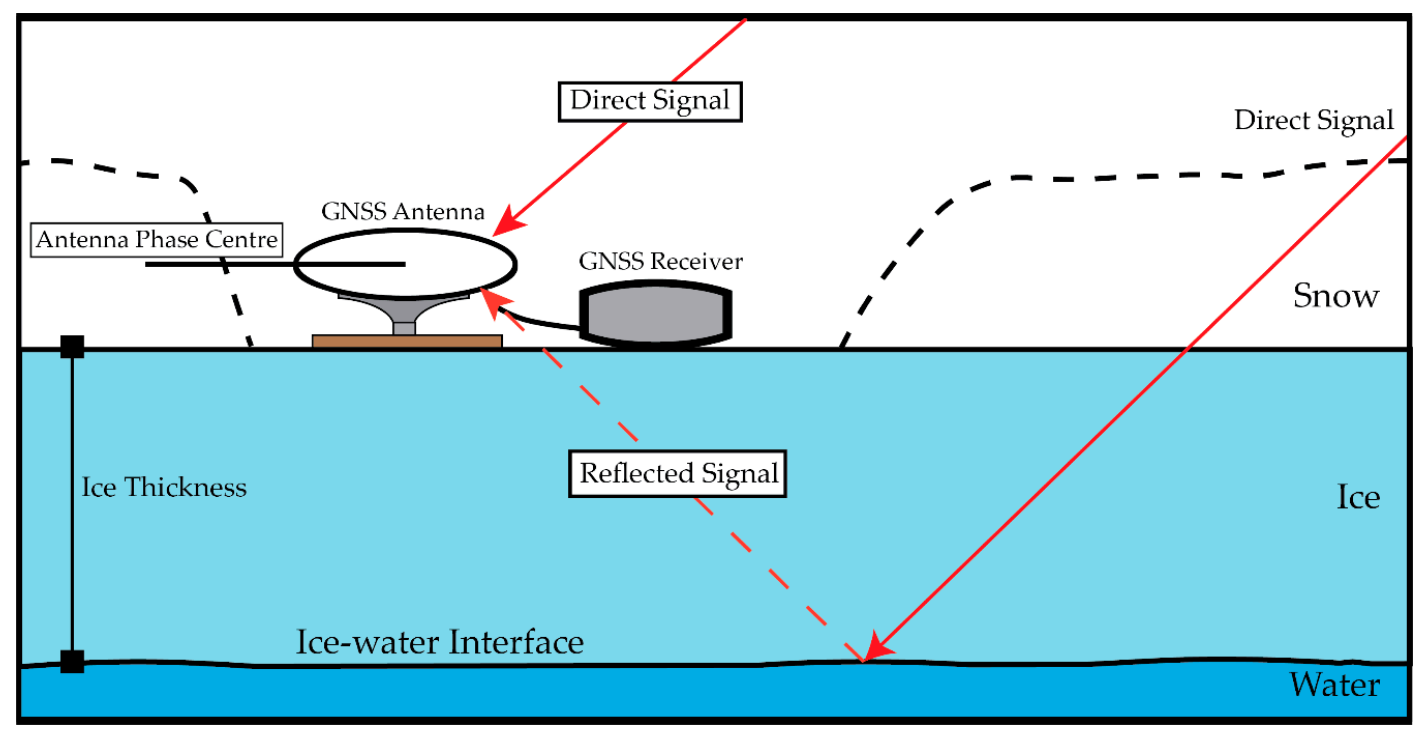

Figure 2. Principle behind the GNSS-IR retrieval approach for the estimation of ice thickness showing the GNSS reflected signal at the ice-water interface.

\subsection{Experiment Setup}

GPS data were collected from modular (antenna and receiver) GNSS stations installed close to locations of manual ice thickness measurements between 8 and 22 March in 2017 and 2019. The systems were not initially deployed for GNSS-IR purposes, but rather as control points in support of airborne and satellite synthetic aperture radar (SAR) investigations on lake ice. GNSS antennas/receivers were installed at 14 lake ice sites located in the Northwest Territories, Canada (Figure 3; Table 1). The systems consisted of dual-frequency TRIMBLE NETR9 receivers and AshTech Pinwheel (model ASH701975.01A) antennas with $1 \mathrm{~Hz}$ sampling rate. Snow was cleared from a roughly $1 \mathrm{x} 1 \mathrm{~m}$ patch so that the antenna could be placed directly on the ice surface (phase centre situated $0.071 \mathrm{~m}$ above the top of the ice surface) (Figure 4). Since reflected signals at low elevation angles easily interfere with line-of-sight signals [16], data were collected only from GPS satellites from low elevation angles (5 to $30^{\circ}$ ). The software package introduced in [17] was used to extract SNR data from raw data files. Based on the average ice thickness of $0.88 \mathrm{~m}$ measured from all sites, the first Fresnel zone has a major axis length of about $20.22 \mathrm{~m}$ and a minor axis length of about $1.76 \mathrm{~m}$ with the lowest GPS satellites elevation angle of $5^{\circ}$, and $1.21 / 0.61 \mathrm{~m}$ (major/minor axis) with the larger elevation angle of $30^{\circ}$. The process described in Section 2.1 was used to estimate ice thickness for all sites. Manual measurements of ice thickness were taken by drilling boreholes in the ice using ice augers. Ice thickness was determined using a tape measure with an ice thickness gauge to the nearest $0.01 \mathrm{~m}$. Meteorological data for 2017 and 2019 were extracted for the two Environment and Climate Change Canada (ECCC) stations nearest the study sites, "Inuvik Climate" and "Yellowknife Airport" $[18,19]$ to identify days experiencing above-freezing air temperatures that could have an impact on the quality of GPS ice thickness retrievals. 


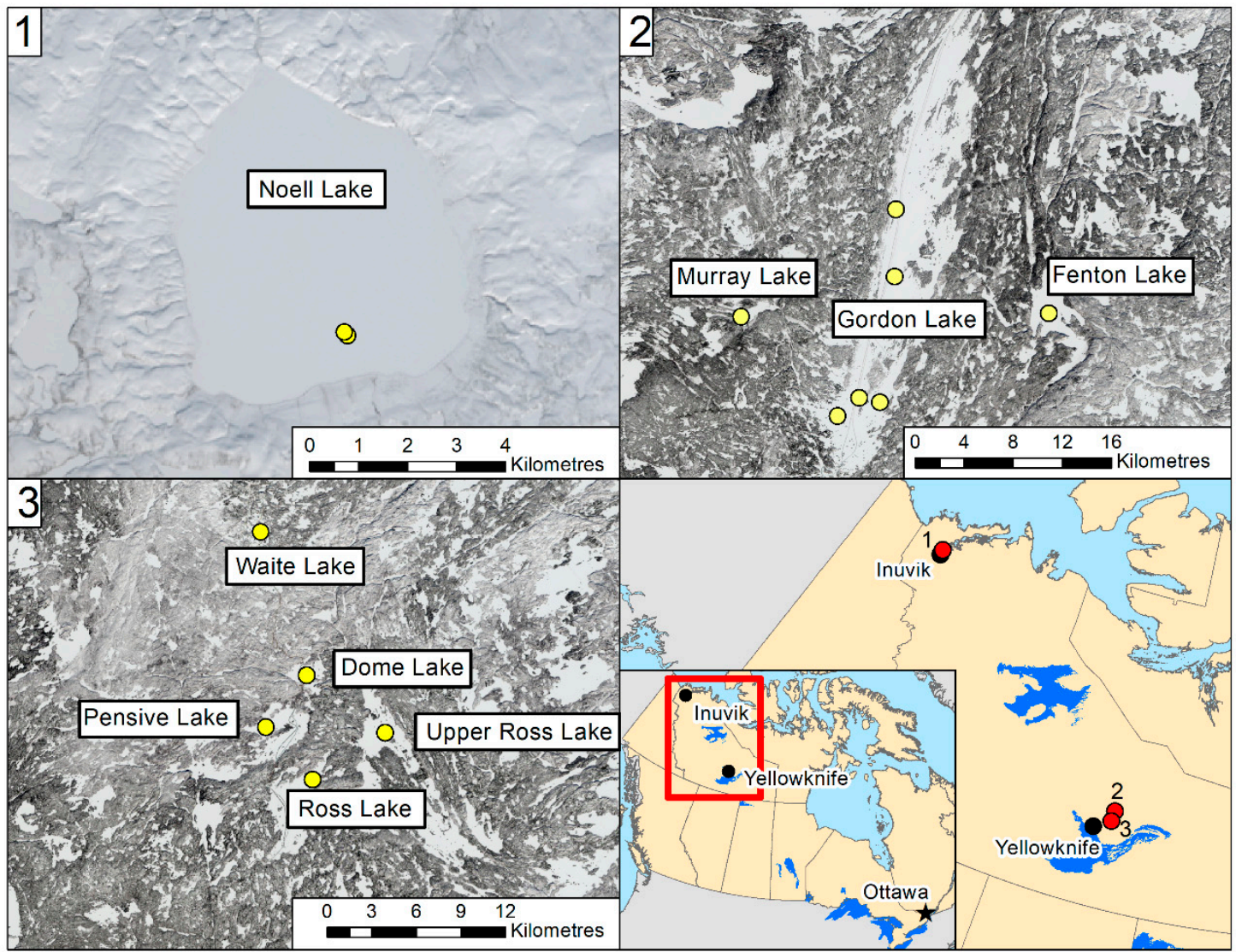

Figure 3. Location of modular GNSS stations deployed at lake ice sites, Northwest Territories, Canada.

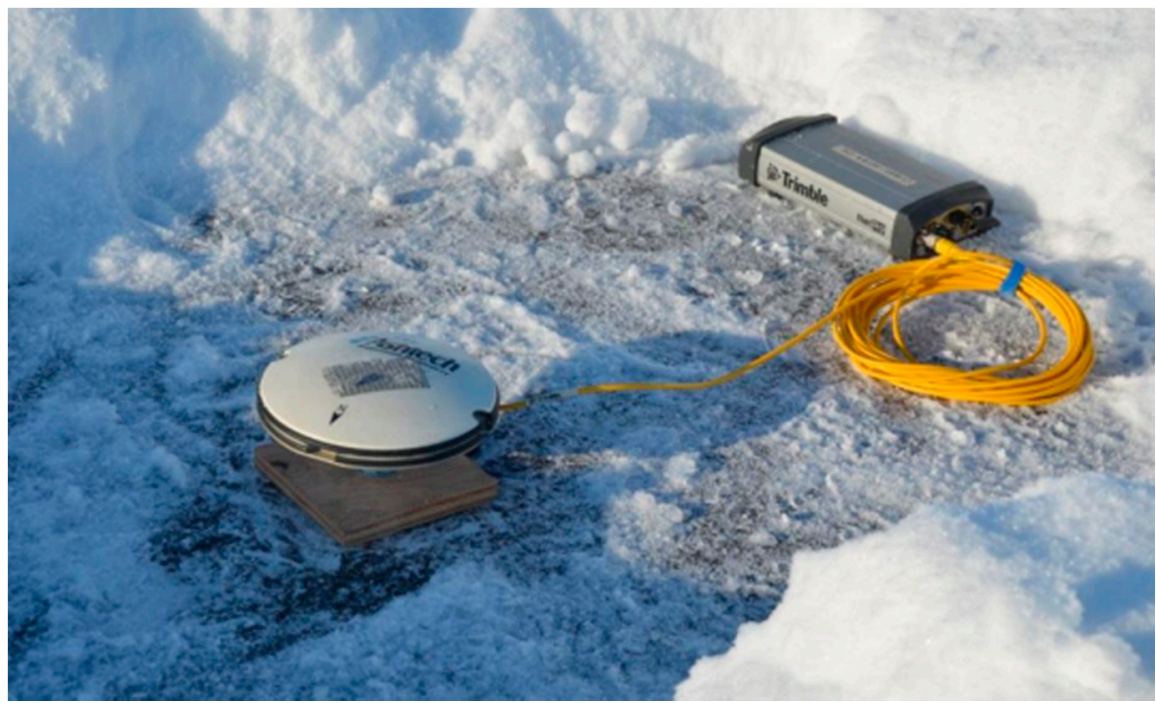

Figure 4. GNSS antenna and receiver setup on the lake ice surface.

\section{Results and Discussion}

Following the retrieval procedure described in Section 2.1, ice thickness was estimated at each of the 14 sites (Figure 5). For all sites combined, the mean absolute error (MAE) is $0.05 \mathrm{~m}$, mean bias error (MBE) is $-0.01 \mathrm{~m}$, and the root mean square (RMSE) is $0.07 \mathrm{~m}$. The obtained RMSE from this method is an improvement compared to best estimates of ice thickness from Great Bear and Great Slave Lakes, which showed a RMSE of $0.19 \mathrm{~m}$ [6]. The negative MBE indicates slight underestimation of retrieved 
ice thicknesses overall. The correlation between in-situ measurements and GNSS-IR retrievals is 0.66 (Figure 6), which fits in the range for previous satellite-based estimates at $>0.65$ [7].

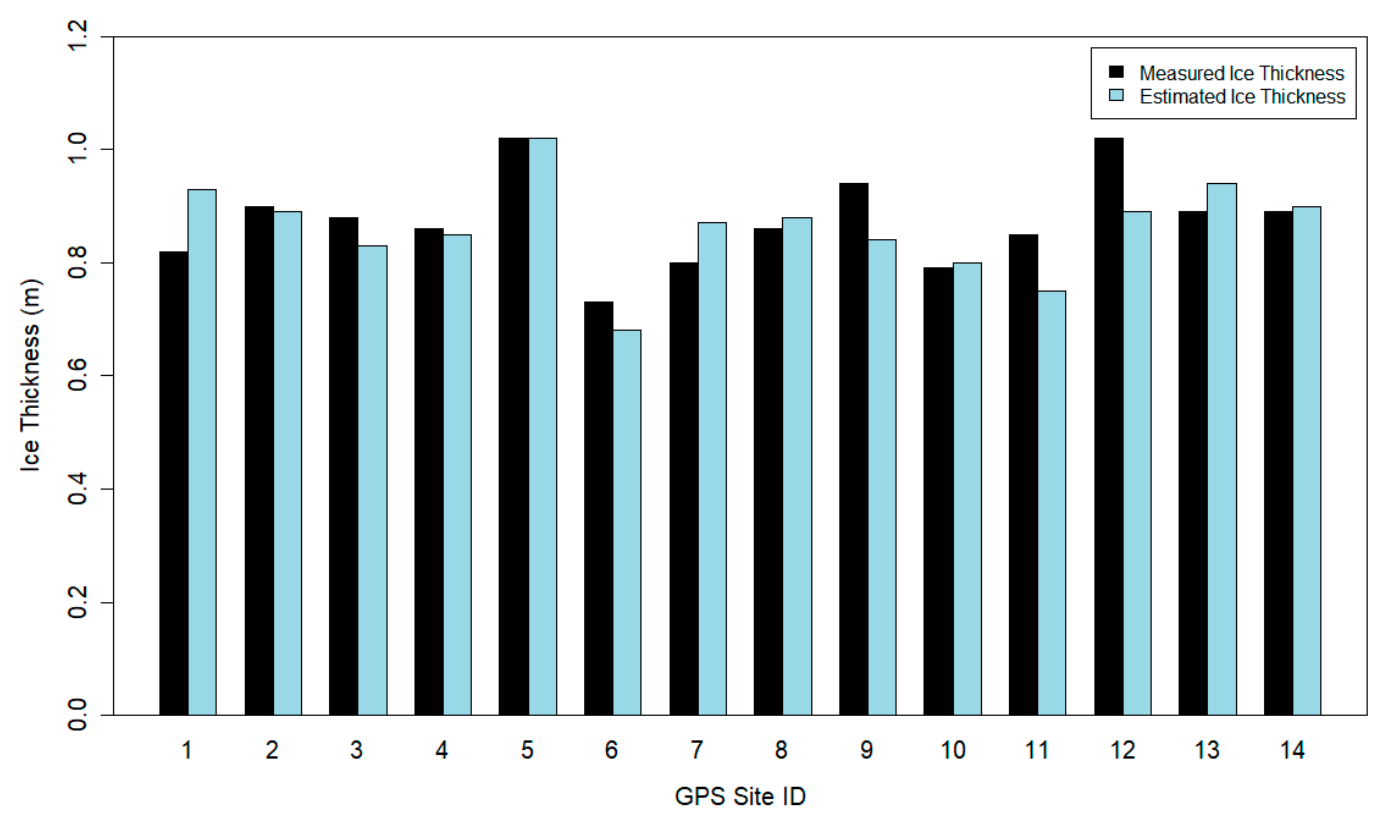

Figure 5. Comparison between estimated ice thickness from GPS-IR and measured ice thickness at each site location.

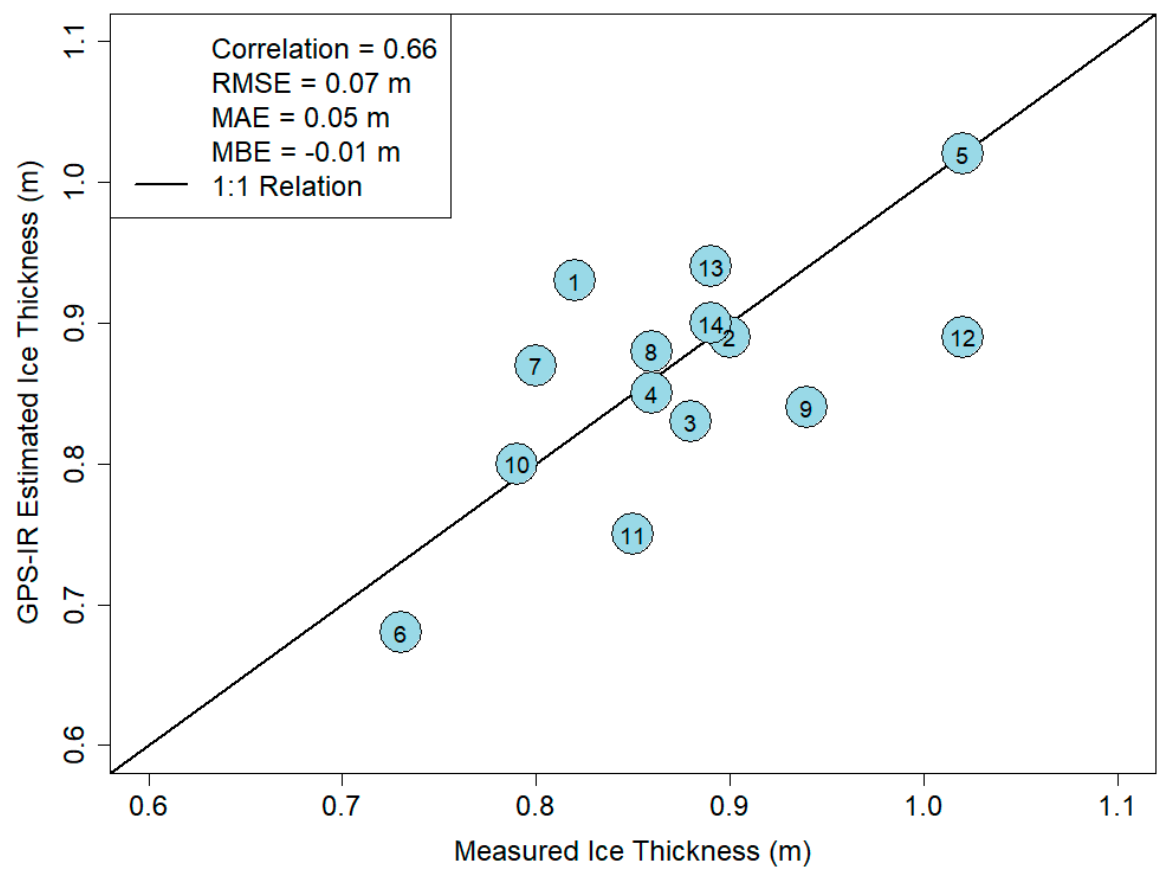

Figure 6. Correlation between in-situ measurements and GPS-IR retrievals.

Temperature records from the two ECCC stations provide insight into likely sources of larger error observed for some retrievals. These stations show that temperatures during or 2-3 days prior to coincident GPS-IR and ice thickness measurements reached $0{ }^{\circ} \mathrm{C}$ or above, particularly for sites at Pensive, Ross, and Upper Ross Lake (sites 7, 9, and 12) (Figure 7). Above-freezing daytime (maximum) temperatures led to melt followed by possible refreezing (minimum) at night. These conditions affected the GPS signals leading to larger retrieval errors (maximum of $0.13 \mathrm{~m}$ ) as these temperature fluctuations 
during the 2019 field campaign resulted in snow surface melt and possibly within layers above the ice surface. These layers have a higher water content and act as additional sources of L-band reflection for direct GPS signals. Therefore, this added reflection can add noise to the measured signals and cause a decrease in the accuracy of the estimation of ice thickness. This was not found to be an issue for data collected in 2017 , as the average temperature was $-22.6{ }^{\circ} \mathrm{C}$. Roughness of the ice-water interface may have an impact on the retrieved estimates. However, for the purpose of this research letter, the interface was assumed planar. Roughness of the ice-water interface for lake ice is difficult to retrieve and is an area of ongoing research. While other factors (i.e., snowpack and ice structure) may have affected the accuracy of estimated values (sites 1 and 11), further field information is needed to understand the extent of this impact and should be an area of future study.
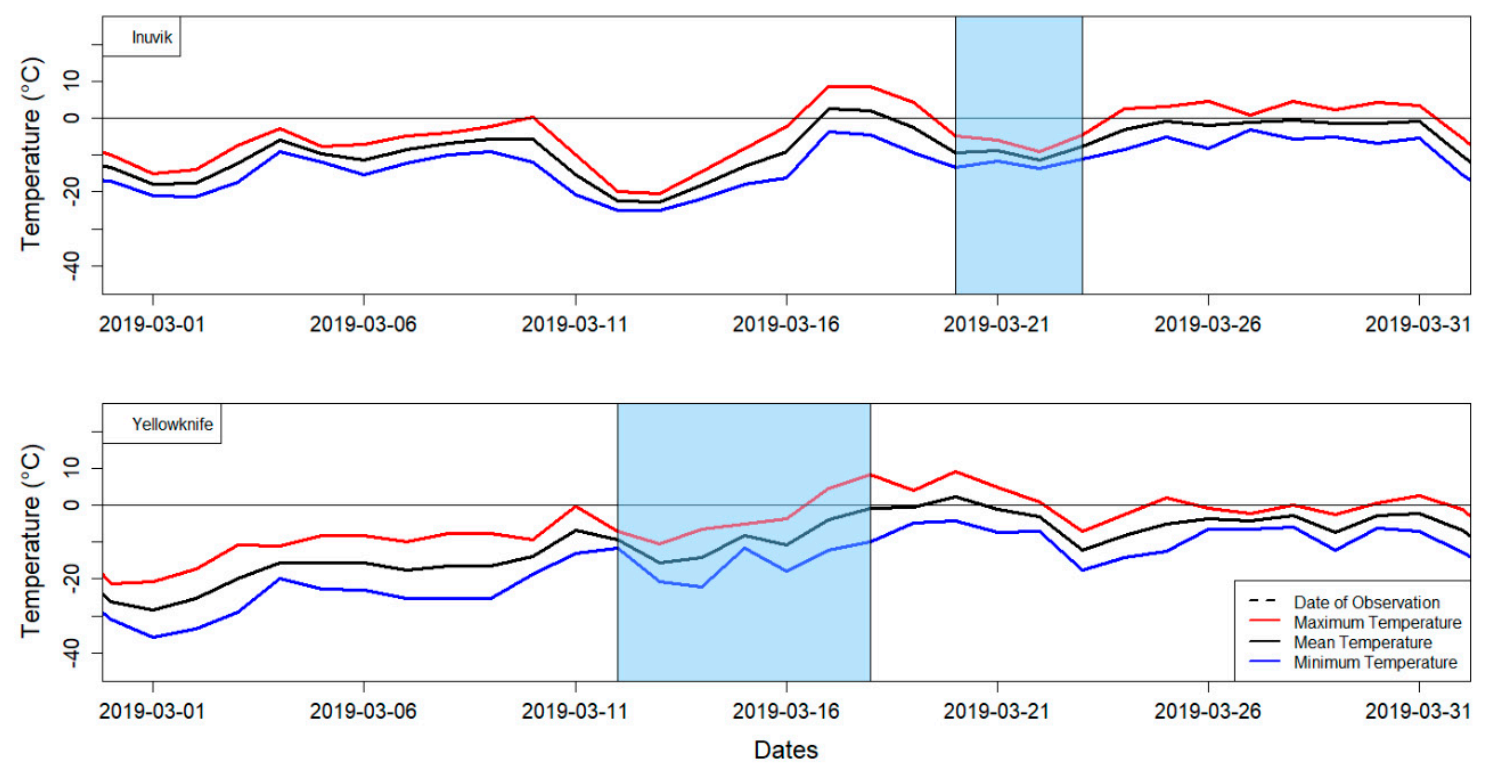

Figure 7. Maximum, minimum, and mean air temperatures recorded at Inuvik (top panel) and Yellowknife (bottom panel) during the 1 January-31 May 2019 period. Shaded boxes correspond to field measurement periods when GPS data and ice thickness measurements were collected.

\section{Conclusions and Future Work}

In addition to other applications examined up until now, this study suggests that GPS/GNSS-IR can be employed as a low-cost and reliable remote sensing approach to estimate lake ice thickness. This method is also beneficial over spaceborne passive microwave estimates of ice thickness as it allows for finer-scale estimates and can be used for small and medium size lakes. Among different frequency retrieval methods, LS-HE is used in this experiment, because it allows for the use of data at unequal time intervals. Ice thickness was estimated using a GNSS-IR approach at 14 lake ice sites and compared to in-situ measurements. The RMSE of the results is $0.07 \mathrm{~m}$, the MBE is $-0.01 \mathrm{~m}$, and the MAE is $0.05 \mathrm{~m}$, which is an improvement compared to previous estimates on large lakes made using passive microwave and radar altimetry data [6,7]. Moreover, a correlation of 0.66 is found between GPS-IR retrievals and in-situ measurements. Temperature records from weather stations located close to the locations show that higher temperatures, which can lead to snow surface melt and produce layers with higher water content, likely impacted the accuracy of ice thickness estimation. Further development of this method could allow for the development of a network of GNSS-IR station that may supplement current measurements of ice thickness along crucial ice routes.

It is also worth noting that this study focused on measurements at high-latitude lake sites that experience more consistent (colder) winter conditions compared to mid latitudes. At lower latitudes, mid-winter thaw and rainfall events are more common throughout the winter season [20]. This means 
that unlike the lakes presented in this study, where the main reflective surface was the ice-water interface as expected under cold conditions, additional reflective surfaces (slush/water layers, ice layers in the snowpack, and varying ice types) may be present in the snowpack or upper ice layers of lake ice cover at lower latitude lake locations. These effects should be studied in future research. Moreover, measurements were only obtained during late-winter field campaigns (March 2017 and 2019); therefore, a limitation of this study is that we do not know with certainty how well the retrieval approach would perform from initial ice formation with thin ice in late-fall/winter until just before melt onset in spring. Although the correlation between estimated and measured ice thickness is relatively high and retrieval errors are low, further research is needed to determine the consistency of the retrievals throughout the ice season.

Future experiments to expand on this novel work should involve the establishment of a semi-permanent station mounted on mast along the shore of a lake to observe the GNSS-IR reflected signals to lake ice throughout one or more full ice seasons. The additional height of the mast would allow for the retrieval of ice thickness over a larger area compared to placing the antenna directly on the ice surface as was done in this initial experiment [21]. Additionally, this setup can include tests of different antenna orientations, such as a side-looking antenna as described by [22] or the three-antenna approach (one zenith and two side-looking) as described by [14]. The establishment of a semi-permanent station would provide valuable information on how the approach proposed herein could be used to monitor lake ice growth and decay. Furthermore, supplemental field measurements would lead to a better understanding of how the GNSS-IR reflected signals are impacted by ice and overlying snow properties under colder and warmer weather conditions (e.g., snow surface melt, slushing at the snow-ice interface and snow-ice formation following refreeze of slushy layers) and uncertainty characterization in ice thickness retrievals. In addition to field measurements, forward modelling using radiative transfer models, such as the Snow Microwave Radiative Transfer (SMRT) model [23], will help to further identify uncertainties in the estimate of ice thickness. An assessment of the various sources of uncertainty is a necessary step towards the implementation of a GNSS-IR network of stations where lake ice thickness estimates could be obtained on a regular basis across various regions of northern countries such as Canada.

Author Contributions: Conceptualization, C.R.D. and Y.G.; methodology, Y.G. and C.P.; software, Y.G.; validation, Y.G., J.M., A.T., J.J.v.d.S. and H.D.; formal analysis, Y.G., C.R.D., and J.M.; investigation, Y.G. and C.R.D.; resources, C.R.D. and J.J.v.d.S.; data curation, Y.G. and J.J.v.d.S.; writing-original draft preparation, Y.G., C.R.D., J.M.; writing-review and editing, Y.G., C.R.D., J.M., A.T., J.J.v.d.S., H.D., and C.P.; visualization, Y.G. and J.M.; supervision, C.R.D.; project administration, C.R.D.; funding acquisition, C.R.D. and J.J.v.d.S. All authors have read and agreed to the published version of the manuscript.

Funding: This research was supported by the Global Water Futures research program (Transformative sensor Technologies and Smart Watersheds project), NSERC Discovery Grant RGPIN-05049-2017 to C.R.D., and the Polar Continental Shelf Program and Remote Sensing Science Program of Natural Resources Canada to J.J.v.d.S.

Acknowledgments: The authors would like to acknowledge the Tibbitt-to-Contwoyto Winter Road (TCWR) Joint Venture Ltd., the Aurora Research Institute (ARI), and the Northwest Territories Geoscience Office for the logistical support provided.

Conflicts of Interest: The authors declare no conflict of interest.

\section{References}

1. Brown, L.C.; Duguay, C.R. The Response and Role of Ice Cover in Lake-Climate Interactions. Prog. Phys. Geogr. 2010, 34, 671-704. [CrossRef]

2. Knoll, L.B.; Sharma, S.; Denfeld, B.A.; Flaim, G.; Hori, Y.; Magnuson, J.J.; Straile, D.; Weyhenmeyer, G.A. Consequences of Lake and River Ice Loss on Cultural Ecosystem Services. Limnol. Oceanogr. Lett. 2019, 4, 119-131. [CrossRef]

3. Brown, L.C.; Duguay, C.R. A Comparison of Simulated and Measured Lake Ice Thickness Using a Shallow Water Ice Profiler. Hydrol. Process. 2011, 25, 2932-2941. [CrossRef] 
4. Murfitt, J.C.; Brown, L.C.; Howell, S.E.L. Estimating Lake Ice Thickness in Central Ontario. PLoS ONE 2018, 13, e0208519. [CrossRef]

5. Gunn, G.E.; Duguay, C.R.; Brown, L.C.; King, J.; Atwood, D.; Kasurak, A. Freshwater Lake Ice Thickness Derived Using Surface-Based X- and Ku-Band FMCW Scatterometers. Cold Reg. Sci. Technol. 2015, 120, 115-126. [CrossRef]

6. Kang, K.-K.; Duguay, C.R.; Lemmetyinen, J.; Gel, Y. Estimation of Ice Thickness on Large Northern Lakes from AMSR-E Brightness Temperature Measurements. Remote Sens. Environ. 2014, 150, 1-19. [CrossRef]

7. Beckers, J.F.; Casey, J.A.; Haas, C. Retrievals of Lake Ice Thickness from Great Slave Lake and Great Bear Lake Using CryoSat-2. IEEE Trans. Geosci. Remote Sens. 2017, 55, 3708-3720. [CrossRef]

8. Chew, C.C.; Small, E.E.; Larson, K.M.; Zavorotny, V.U. Effects of Near-Surface Soil Moisture on GPS SNR Data: Development of a Retrieval Algorithm for Soil Moisture. IEEE Trans. Geosci. Remote Sens. 2014, 52, 537-543. [CrossRef]

9. Larson, K.M. GPS Interferometric Reflectometry: Applications to Surface Soil Moisture, Snow Depth, and Vegetation Water Content in the Western United States. WIRES Water 2016, 3, 775-787. [CrossRef]

10. Strandberg, J.; Hobiger, T.; Haas, R. Coastal Sea Ice Detection Using Ground-Based GNSS-R. IEEE Geosci. Remote. Sens. Lett. 2016, 14, 1552-1556. [CrossRef]

11. Jacobson, M.D. Snow-Covered Lake Ice in GPS Multipath Reception-Theory and Measurement. Adv. Space Res. 2010, 46, 221-227. [CrossRef]

12. Jacobson, M.D. Potential for Estimating the Thickness of Freshwater Lake Ice by GPS Interferometric Reflectometry. J. Geogr. Geol. 2015, 7, 10-19. [CrossRef]

13. Amiri-Simkooei, A.; Tiberius, C.; Teunissen, P. Assessment of Noise in GPS Coordinate Time Series: Methodology and Results. J. Geophys. Res. 2007, 112, B07413. [CrossRef]

14. Cardellach, E.; Fabra, F.; Rius, A.; Pettinato, S.; D'Addio, S. Characterization of Dry-Snow Sub-Structure using GNSS Reflected Signals. Remote Sens. Environ. 2012, 124, 122-134. [CrossRef]

15. Engram, M.; Anthony, K.W.; Meyer, F.J.; Grosse, G. Characterization of L-Band Synthetic Aperture Radar (SAR) Backscatter from Floating and Grounded Thermokarst Lake Ice in Arctic Alaska. Cryosphere 2013, 7, 1741-1752. [CrossRef]

16. Zhou, W.; Liu, L.; Huang, L.; Yao, Y.; Chen, J.; Li, S. A new GPS SNR-based combination approach for land surface snow depth monitoring. Sci. Rep. 2019, 9, 1-20. [CrossRef]

17. Roesler, C.; Larson, K.M. Software Tools for GNSS Interferometric Reflectometry (GNSS-IR). GPS Solut. 2018, 22, 80. [CrossRef]

18. Environment and Climate Change Canada. Inuvik Climate Historical Daily Data 2017 and 2019. Available online: https://climate.weather.gc.ca/historical_data/search_historic_data_e.html (accessed on 26 March 2020).

19. Environment and Climate Change Canada. Yellowknife Airport Historical Daily Data 2017 and 2019. Available online: https://climate.weather.gc.ca/historical_data/search_historic_data_e.html (accessed on 26 March 2020).

20. Ariano, S.S.; Brown, L.C. Ice Processes on Medium-Sized North-Temperate Lakes. Hydrol. Process. 2019, 33, 2434-2448. [CrossRef]

21. Larson, K.M.; MacFerrin, M.; Nylen, T. Brief Communication: Update on the GPS reflection technique for measuring snow accumulation in Greenland. Cryosphere 2020, 14, 1985-1988. [CrossRef]

22. Alonso-Arroyo, A.; Camps, A.; Park, H.; Pascual, D.; Onrubia, R.; Martín, F. Retrieval of Significant Wave Height and Mean Sea Surface Level Using the GNSS-R Interference Pattern Technique: Results from a Three-Month Field Campaign. IEEE Trans. Geosci. Remote Sens. 2015, 53, 3198-3209. [CrossRef]

23. Picard, G.; Sandells, M.; Löwe, H. SMRT: An Active-passive Microwave Radiative Transfer Model for Snow with Multiple Microstructure and Scattering Formulations (v1.0). Geosci. Model Dev. 2018, 11, 2763-2788. [CrossRef]

(C) 2020 by the authors. Licensee MDPI, Basel, Switzerland. This article is an open access article distributed under the terms and conditions of the Creative Commons Attribution (CC BY) license (http://creativecommons.org/licenses/by/4.0/). 